\title{
ATELLÂ \\ Pluriatividade em assentamentos rurais: forma de exclusão, inclusão ou permanência no campo?
}

\author{
Pluriactivity in rural settlements: is it a kind of exclusion, \\ inclusion or permanence in the field?
}

Pluriactivité dans les agglomérations rurales : une façon
d'exclusion, d'inclusion ou de permanence aux champs?

Juliana Abadia do Prado Soares

Universidade Federal de Goiás - Regional Jataí

jupraso@bol.com.br

Dimas Moraes Peixinho

Universidade Federal de Goiás - Regional Jataí

dimaspeixinho@yahoo.com.br

\begin{abstract}
Resumo
A organização da produção no rural tem sido marcada por uma diversificação que vai da especialização à pluralidade de atividades, da produção em grande empresa à produção em pequenas propriedades. A organização na pequena propriedade voltada para agricultura familiar produz uma dinâmica que envolve atividades agrícolas, para-agrícolas e não agrícolas. A combinação de práticas agrícolas/para-agrícolas e não agrícolas, em uma mesma propriedade, aparece como uma opção para os agricultores familiares assentados, prática que é denominada como pluriatividade. A intenção desse artigo é analisar diferentes perspectivas buscando compreender o papel da pluriatividade para o agricultor em condição de assentamentos. Pretende-se destacar os pontos positivos e negativos das práticas pluriativas e, por fim, responder se a pluriatividade em assentamentos pode ser uma forma de exclusão, inclusão ou permanência no campo, a partir de estudos teóricos e empíricos. O recorte espacial é Microrregião Geográfica Sudoeste de Goiás, nos Assentamentos Agrovila Rio Verdinho no munícipio de Rio Verde (GO) e Nossa Senhora de Guadalupe no munícipio de Jataí (GO).

Palavras-chaves: Pluriatividade; Agricultura familiar; Assentamentos.
\end{abstract}

\begin{abstract}
The organization of the rural production has been defined by a diversification which varies from specialization to the plurality of activities, from production in large companies to the production in small ones. The organization in a small property
\end{abstract}


focused on family farming produces a dynamics which involves agricultural activities, secondary activities and non-agricultural ones. The combination of agricultural/secondary activities and non-agricultural activities, in the same property, seems like an option for settled family farmers, a practice which is called pluriactivity. The objective of this article is to analyze different perspectives seeking to understand the role of the pluriactivity for the farmer in settlement conditions. It's considered as an objective to highlight positive and negative aspects of pluriactive practices and, therefore, be able to answer if the pluriactivity in settlements can be a kind of exclusion, inclusion or permanence in the field, from theoretical and empirical studies. The studied area is the Geographic Microregion of South-west of Goiás state, in the settlements of Agrovila Rio Verdinho in the municipality of Rio Verde (GO) and Nossa Senhora de Guadalupe in the municipality of Jataí (GO).

Keywords: Pluriactivity; Family farming; Settlements.

\section{Résumé}

L'organisation de la production rurale a été marquée par une diversification qui s'étend de la spécialisation jusqu'à la pluralité des activités; de la production dans une grande entreprise à la production dans les petites propriétés. L'organisation à la petite propriété tournée vers l'agriculture familiale produit une dynamique qui concerne les activités agricoles, les activités secondaires et les activités nonagricoles. La combinaison des pratiques agricoles/activités secondaires et nonagricoles, dans une même propriété, apparaît comme une option pour les agriculteurs familiales assis, dont cette pratique appelée comme pluriactivité. L'objectif de cet article est d'analyser les différentes perspectives en cherchant comprendre le rôle de la pluriactivité pour l'agriculteur en condition de règlements. Il vise souligner les points positifs et négatifs des pratiques pluriactives, et finalement, répondre si la pluriactivité dans les règlements peut être une manière d'exclusion, d'inclusion ou de permanence aux champs, à partir des études théoriques et empiriques. Le domaine étudié est la Microrégion Géographique du Sud-ouest de Goiás, aux règlements appelées Agrovila Rio Verdinho, situé à Rio Verde (GO) et Nossa Senhora de Guadalupe, à Jataí (GO).

Mots-clés: Pluriactivités ; Agriculture familiale ; Agglomérations rurales.

\section{Introdução}

Nas últimas décadas, especialmente a partir dos anos de 1970, temos assistido uma profunda mudança no "rural" brasileiro e na forma de se produzir, com uso de técnicas que vem se renovando ao longo dessas décadas. "O espaço rural tem sido marcado por uma revitalização como meio de vida e de trabalho", Teixeira (2012, p.11). Essas mudanças vão além da forma de se produzir, interferindo também no modo de vida, nas atividades desenvolvidas e até mesmo nos atores sociais que compõem esse novo campo. Esse campo urdido por novas formas de produção entrelaça campo e cidade, criando, adaptando ou reconfigurando o espaço para atender suas demandas.

A organização da produção no rural tem sido marcada por uma diversificação a partir da especialização à pluralidade de atividades, da produção em grandes empresas e à produção em pequenas propriedades. Essa diversidade envolvendo as formas e a organização da produção tem sido analisada pelos estudiosos a partir de vários ângulos. As interpretações variam conforme as perspectivas teóricas, históricas e espaciais compreendidas por diferentes 
autores. Mas, mais do que as interpretações, a realidade é múltipla e requer sempre atualizações que contribuam para a compreensão da realidade.

A agricultura familiar é um segmento de grande importância no campo brasileiro, responsável em prover $70 \%$ dos alimentos de origem vegetal e animal que são consumidos diariamente, entretanto, com a inserção do capitalismo no campo há uma valorização das terras, uma produção em larga escala voltada para o mercado externo realizado pelo agricultor empresarial. Nesse contexto, o agricultor familiar perde espaço físico e tende a buscar novas formas de sobreviver, desenvolvendo atividades nem sempre ligadas ao campo, facilitadas pelas novas influências que permeiam o rural. Não perdendo o foco das práticas agrícolas, as atividades não agrícolas também podem ser desenvolvidas por esses agricultores familiares, o que a partir da década de 1990 passa a ser discutida no Brasil com a denominação de pluriatividade. Para Schneider (2007, p.7), os estudos realizados sobre pluriatividade permitem concluir que se trata de um fenômeno estável e diversificado no meio rural, embora seja uma prática realizada em décadas anteriores, apenas recentemente passou a ser estudado sob esta denominação.

A pluriatividade teve seus estudos iniciados na Europa, mais precisamente na França. Somente nos anos de 1990 esse tema passa a ser debatido no Brasil. Embora sendo um termo recente no campo de discussões acadêmicas, a forma pioneira da pluriatividade já foi alvo de discussão de Kaustky (1980) como "trabalho acessório" e por Chayanov (1974) como "por outras atividades não agrícolas", ainda no fim do século XIX e início do século $\mathrm{XX}$. A diferença entre as práticas de atividades agrícolas e não agrícolas desenvolvidas em um mesmo estabelecimento rural em décadas anteriores para a pluriatividade dos anos atuais, pode ser entendido a partir do próprio contexto socioeconômico específico, identificado como "ruralidades contemporâneas". (TEIXEIRA, 2012, p.14).

Diversos fatores levam a prática da pluriatividade, dentre eles tem-se de um lado fatores internos como o próprio ciclo vital e as demandas sociais de consumo (que aumentam com o avanço tecnológico e influência da mídia no campo), de outro lado fatores externos como o elevado custo de produção e a queda nos preços agrícolas. O motivo que leva a pluriatividade pode ser uma questão emergencial, voltado à sobrevivência, para evitar o avanço da pobreza ou mesmo como aparato necessário para a própria permanência no campo. Além disso, pode ser algo opcional que tende a fortalecer a renda familiar, proporcionando melhoria de vida ou até mesmo acumulação financeira.

Há uma mudança no cenário rural com o surgimento dos agricultores familiares pluriativos que emergem a novos "atores sociais" residentes no campo, como: desempregados, pensionistas, aposentados, comerciantes, empregados das indústrias, prestadores de serviços, funcionários públicos, empregados em grandes propriedades dentre outros.

Diante do cenário atual os avanços tecnológicos, principalmente voltados para os meios de comunicação, de transporte e investimentos em infraestrutura, possibilitam a moradia no campo e trabalho nas cidades, tornando esse fato cada vez mais comum, sendo um importante aliado do agricultor familiar. 
Nascimento (2008, p.29) afirma que "a pluriatividade é um fenômeno social "encontrável" em todo o território nacional, sendo que haverá uma explicação para sua especificidade, de acordo com a realidade de cada região brasileira". Partindo desse pressuposto discute-se a viabilidade das práticas pluriativas na Microrregião Geográfica Sudoeste de Goiás. Região em que o agronegócio possui expressividade em nível nacional, a bovinocultura de corte e leiteira tem aprimoramento genético, destacando-se no Brasil e em outros países, possui importantes parques industriais e comerciais, gerando emprego e renda. Entretanto, a agricultura familiar se faz presente e tem uma grande importância econômica e social, provendo uma alimentação mais saudável a um menor custo, além de gerar empregos diretos e indiretos. Justifica-se a opção em pesquisar a agricultura familiar em regime de assentamento, isso porque, apesar da pequena área ocupada, o número de assentamentos é expressivo nessa microrregião.

Esse artigo é parte da dissertação de Mestrado do Programa de Pós-graduação em Geografia da Universidade Federal de Goiás Regional Jataí, intitulada "A pluriatividade na agricultura familiar: estudos nos assentamentos Nossa Senhora do Guadalupe em Jataí (GO) e Agrovila Rio Verdinho em Rio Verde (GO)"'

Objetiva-se neste texto, promover um debate teórico sobre a viabilidade da prática pluriativa na agricultura familiar e em assentamentos, busca-se compreender se essas práticas são formas de exclusão, inclusão ou permanência no campo, através de uma analise de cunho teórico e empírico, a partir de autores ligados a Geografia Agrária e a Sociologia Rural com destaque para: Carneiro (1996,1999,2012), Fuller (1990), Kageyama (1999), Schneider (2003), Candiotto (2007), Abramovay (1992), Anjos (2003), Calaça (2010), Alentejano (1999), Oliveira (2007), Junior (1979 ), Kaustky (1980), Lamarche (1998), Teixeira (2009), Wanderley (2011), Campanhola e Graziano da Silva (2000), Veiga (1991), Martins (1981), Oliveira (2007).

Espera-se que essa análise possa contribuir para compreensão da dinâmica espacial dos assentamentos, entender como as estratégias organizadas pelos agricultores familiares são desenvolvidas para se manterem a partir das atividades pluriativas.

\section{Origem e conceituação da pluriatividade}

A pluriatividade começa a ser discutida na década de 1970 na França, quando se inicia o movimento de resistência familiar camponesa, que ganha força nos anos 1980, "quando a crise da agricultura europeia (crise de superprodução) levou muitos agricultores a inverterem o processo de especialização, buscando diversificar não apenas culturas, mas também atividades" (Alentejano, 1999, p.153). A discussão acerca do tema foi inaugurada na França com o colóquio organizado pela Association Ruraliste Française (ARF), cujos trabalhos foram publicados sob o título La pluriactivité dans les familles agricoles, Paris, ARF, 1984; destaca-se também o colóquio organizado pela Arkketon Research, Inra \& IAM (1987), uma importante revisão do debate francês é trazida para Brasil através de Carneiro

\footnotetext{
${ }^{1}$ Pesquisa financiada pela bolsa de estudos da CAPES - Coordenação de aperfeiçoamento de Pessoal de Nível Superior.
} 
(1996). Segundo a referida autora nesse período, as práticas de atividades não agrícolas ocorriam devido os seguintes fatores: o tamanho da propriedade, a composição do grupo doméstico e o capital cultural acumulado pela família.

A discussão acerca da pluriatividade no Brasil é nova e de pouca aceitabilidade, sendo a sociologia rural e as ciências agrárias incumbidas dessa tarefa. Schneider (2003 p.101) comenta que "no Brasil, malgrado alguns esforços, o debate sobre a pluriatividade ainda é embrionário. Carneiro (1996 p. 10) afirma que a pluriatividade "[...] é um termo de criação recente do vocabulário técnico, do qual o campo acadêmico se apropriou. Assim, a noção só ganha sentido se for relacionada com a política agrícola que estimulou a especialização da produção e do trabalho". No entanto, a pluriatividade possui um caráter estrutural que perpassa diferentes períodos históricos e situações socioeconômicas distintas.

Por estar se integrando recentemente ao mundo agrário a pluriatividade sofre divergências de conceptualização, deste modo, são necessários alguns esclarecimentos acerca desse tema. Schneider (2003) afirma que em razão desse campo de análise ser ainda recente considera-se oportuna e necessária a recuperação da trajetória do debate sobre a origem e desenvolvimento de alguns termos na literatura internacional.

Baseando em estudos de Schneider (2003, pp.103-105) é possível criar um quadro que permita distinguir alguns termos relacionados ao conceito de pluriatividade, como também apontar semelhanças entre os mesmos como segue Quadro 01:

Quadro 01: Definições de termos internacionais presentes nos estudos sobre pluriatividade.

\begin{tabular}{|c|c|c|c|}
\hline \multicolumn{4}{|c|}{ Termos/definições } \\
\hline Termos & Tradução & Conceito & $\begin{array}{c}\text { Pluriactivitè ou pluriactivity } \\
\text { (pluriatividade) }\end{array}$ \\
\hline $\begin{array}{l}\text { Part-time } \\
\text { farming }\end{array}$ & $\begin{array}{l}\text { Agricultura em } \\
\text { tempo parcial }\end{array}$ & $\begin{array}{c}\text { Pode ser utilizada de forma mais } \\
\text { precisa, para definir situações onde, } \\
\text { devido ao tamanho físico ou a uma } \\
\text { opção de gestão, a unidade produtiva é } \\
\text { cultivada pelo investimento de menos de } \\
\text { um ano completo de trabalho, } \\
\text { considerando apenas o "chefe" de } \\
\text { família. }\end{array}$ & $\begin{array}{l}\text { O termo procura focalizar as } \\
\text { diferentes atividades e } \\
\text { interesses dos indivíduos e } \\
\text { das famílias que vivem na } \\
\text { unidade produtiva. Preocupa- } \\
\text { se tanto com a reprodução } \\
\text { social e a participação no } \\
\text { mercado de trabalho rural, }\end{array}$ \\
\hline $\begin{array}{l}\text { Double } \\
\text { activitè }\end{array}$ & Dupla atividade & $\begin{array}{l}\text { Vem sendo empregada para caracterizar } \\
\text { a combinação das atividades agrícolas } \\
\text { com o emprego em atividades } \\
\text { industriais pelos agricultores, a noção de } \\
\text { dupla atividade passou a ser de uso } \\
\text { corrente na Europa, nos estudos sobre os } \\
\text { camponeses-operários, e sobre o } \\
\text { movimento inverso, chamado de neo- } \\
\text { rural, que caracterizava o retorno de } \\
\text { jovens ao campo, com o objetivo maior } \\
\text { de residir do que de trabalhar no rural. }\end{array}$ & $\begin{array}{l}\text { como com a terra e as } \\
\text { questões agrícolas. A } \\
\text { pluriatividade implica uma } \\
\text { forma de gestão do trabalho } \\
\text { doméstico que sempre inclui } \\
\text { o trabalho agrícola, o que não } \\
\text { quer dizer que esta atividade } \\
\text { seja exclusiva ou mesmo a } \\
\text { mais importante. Outras } \\
\text { atividades podem ser } \\
\text { assumidas com o objetivo de }\end{array}$ \\
\hline
\end{tabular}




\begin{tabular}{|c|c|c|c|}
\hline Termos & Tradução & Conceito & $\begin{array}{c}\text { sustentar ou de dar suporte à } \\
\text { unidade doméstica, ou ainda } \\
\text { serem motivadas por } \\
\text { considerações não }\end{array}$ \\
$\begin{array}{c}\text { Multiple } \\
\text { job } \\
\text { houlding }\end{array}$ & $\begin{array}{c}\text { Unidades } \\
\text { agrícolas que } \\
\text { combinam } \\
\text { múltiplas fontes } \\
\text { de rendimento. }\end{array}$ & $\begin{array}{c}\text { Abarca um conjunto de atividades que } \\
\text { nem sempre são remuneradas em } \\
\text { dinheiro, mas com pagamentos em } \\
\text { espécie, por meio da permuta de } \\
\text { trabalho e outros arranjos informais. }\end{array}$ & $\begin{array}{c}\text { Para considerar uma Unidade } \\
\text { de Produção Familiar leva em } \\
\text { consideração a prática de } \\
\text { atividades não agrícola de um } \\
\text { ou mais membro da família. }\end{array}$ \\
\hline
\end{tabular}

Organização: SOARES, J. A. P. (2016) - Tabela criada a partir de informações retirada de SCHNEIDER (2003 pp. 103 - 105) Teoria Social, Agricultura Familiar e Pluriatividade.

A definição que mais se aproxima da pluriatividade é part-time farming o que os distingue é que pluriatividade refere-se a práticas agrícolas e não agrícolas por algum membro do núcleo familiar, já part-time farming considera apenas o responsável pela família, ou seja, o chefe familiar.

Em razão dessa diversidade de definições a noção de pluriatividade vem sendo questionada por vários autores, que reivindicam "uma delimitação mais rigorosa de um campo de observação tão difuso" Carneiro (1996, p.95). Corroborando com a ideia de Carneiro, Schneider (2003, p.79), a noção de pluriatividade, apesar de polêmica, vem sendo utilizada para descrever o processo de diversificação que ocorre dentro e fora da propriedade, bem como para apontar a emergência de um conjunto de novas atividades que tomam lugar no meio rural.

Fuller (1990) é tido como uma referência mundial no debate teórico sobre pluriatividade, diante desse emaranhado de tentativas de conceituar a pluriatividade a mais coerente definição sobre o tema é que:

A pluriatividade permite reconceituar à propriedade como uma unidade de produção e reprodução, não exclusivamente baseada em atividades agrícolas. As propriedades pluriativas são unidades que alocam o trabalho em diferentes atividades, além da agricultura familiar (homebased farming). [...] A pluriatividade permite separar a alocação do trabalho dos membros da família de suas atividades principais, assim como o trabalho efetivo das rendas. Muitas propriedades possuem mais fontes de renda do que locais de trabalho, obtendo diferentes tipos de remuneração. A pluriatividade, portanto, refere-se a uma unidade produtiva multidimensional, onde se pratica a agricultura e outras atividades, tanto dentro como fora da propriedade, pelas quais são recebidos diferentes tipos de remuneração e receitas (rendimentos, rendas em espécie e transferências). (FULLER, 1990, p. 367).

Com isso Fuller (1990) relembra que a pluriatividade seria uma forma de reprodução familiar, uma vez que, existem propriedades em que há mais "braços" do que funções a serem desenvolvidas, abrangendo uma forma multidimensional de práticas 
empregatícias, onde o agricultor ou membro de sua família poderia trabalhar dentro ou fora da alocação como forma de complemento de renda. Alentejano (1999) afirma que:

A pluriatividade envolve a diversificação das formas de organização, com multiplicação de estratégias complementares de reprodução dos agricultores, como o assalariamento urbano, a transformação industrial ou artesanal da produção agrícola, e o desenvolvimento de atividades terciárias (serviços e lazer) na propriedade rural. (p.155).

\section{Motivação para as práticas pluriativas em assentamentos}

Nos assentados pesquisados dois grupos distintos de trabalhadores foram identificados, de um lado, em sua maioria, são os "excluídos da terra" que retornam ao campo, do outro, moradores urbanos que iniciam uma nova vida no campo, sendo assim é comum deparar com "novos atores sociais" que habitam os assentamentos, como: desempregados, pensionistas, aposentados, comerciantes, empregados das indústrias, prestadores de serviços, funcionários públicos, funcionários em grandes propriedades, pedreiros, padeiros, mecânicos, diaristas, afinal diversas profissões. Conforme Schneider (2007) há uma mudança do mercado de trabalho rural no Brasil.

Não há grande resistência por parte desses "novos atores sociais" na prática de atividades não agrícolas. Vários são os fatores que contribuem para a prática da pluriatividade em assentamentos. Dentre esses destacam fatores externos e fatores internos, representados na Figura 01:

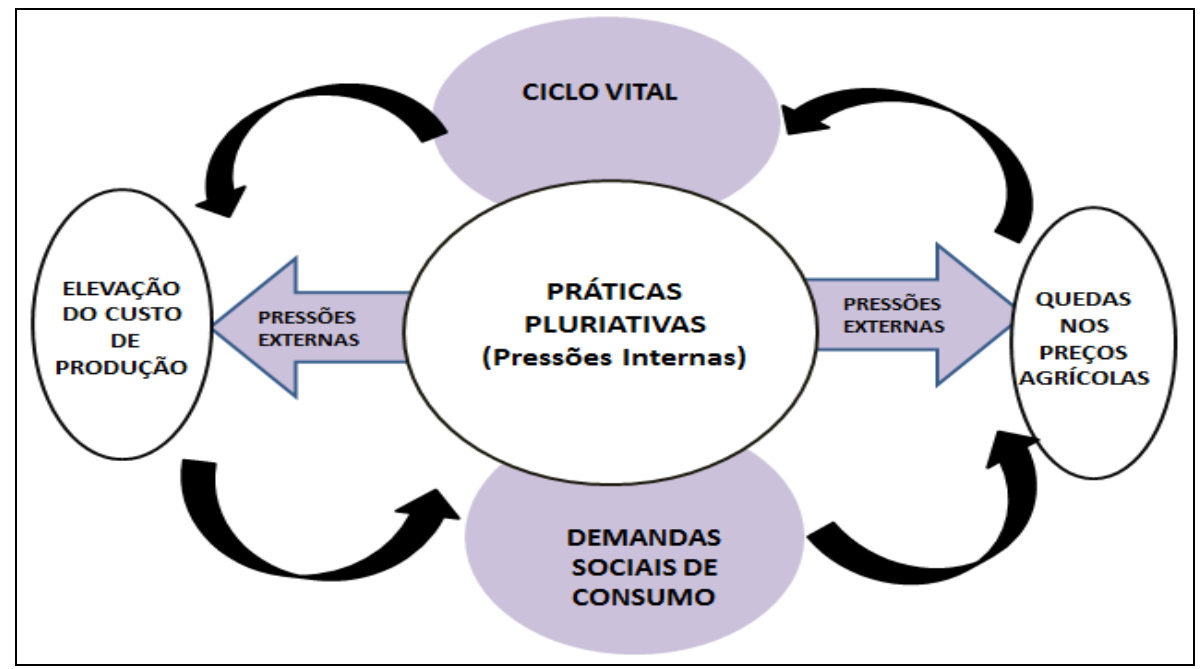

Figura 01: Pressões internas e externas para práticas pluriativas.

Organizado por SOARES, J. A. P (2016). 
Os fatores internos inerentes às práticas pluriativas é o próprio ciclo vital ligado à questão de sobrevivência familiar e ainda as demandas sociais de consumo que variam de acordo com a composição familiar de cada Unidade, que tendem aumentar a partir do avanço tecnológico juntamente com o incentivo das mídias que também chegam até o campo. Já os fatores externos dependem do mercado, como a elevação do custo de produção, que em muitos casos exigem do agricultor familiar alto investimento para um retorno pequeno, e a própria queda nos preços agrícolas que não são estáveis e vão depender do mercado. Segundo Schneider (2007) já se sabe que a pluriatividade se trata de uma estratégia de reprodução social das famílias rurais, que recorrem às atividades externas por diferentes razões (adaptação, reação, estilo de vida), não sendo a pobreza único fator determinante.

Ainda sobre a pluriatividade Schneider (2007) relata que mesmo sendo um fenômeno multideterminado, alguns dos principais fatores que afetam e estimulam a pluriatividade podem ser identificados a partir de várias bibliografias estes fatores podem assim ser representados como na Figura 02:

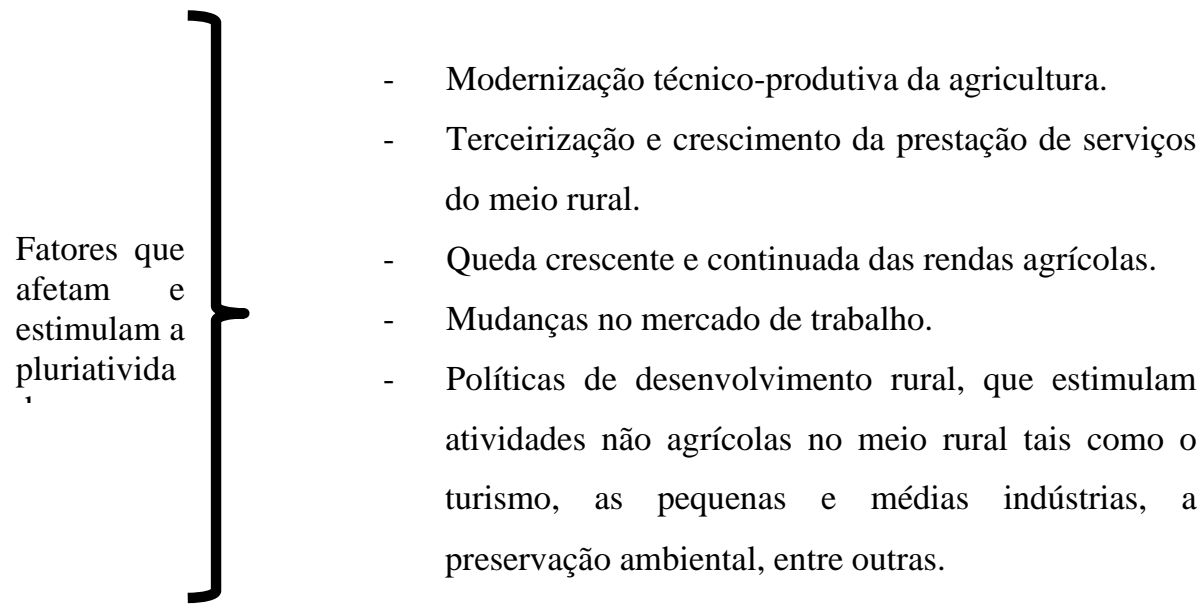

Figura 02: Fatores que afetam e estimulam a pluriatividade.

Fonte: Schneider, 2007, pp. 11-14; Organização: SOARES, J.A.P, 2016.

O primeiro fator em destaque na Figura 02 permite compreender que o emprego de técnicas está cada vez mais avançado na agricultura, a diminuição de mão de obra nas atividades agrícolas gera ociosidade, isto é, o tempo destinado as atividades ligadas ao campo é menor, o que permite ao trabalhador rural desenvolver outro tipo de atividade, que nem sempre será agrícola. Conforme Schneider (2007) a disponibilidade de tecnologias cada vez menos intensivas gera tanto ociosidade de mão-de-obra como subocupação da força de trabalho, tornando-se um fator que estimula os membros das famílias com domicílio rural a buscar outras formas de ocupação. 
No segundo fator destaca-se terceirização e crescimento da prestação de serviços do meio rural, que com os altos custos dos meios de produção, áreas inextensas para produção e ainda baixos lucros, remete o agricultor familiar a terceirizar as atividades agrícolas. Para Laurenti (2000) e Niederle (2007) nos anos recentes, vem se ampliando o processo de subcontratação ou aluguel de máquinas e equipamentos e contratação de serviços de terceiros para execução de tarefas que antes eram realizadas no interior da exploração agropecuária. Esse fato pode estar ligado também ao processo de modernização técnico-produtivo da agricultura.

No terceiro fator à queda crescente e continuada das rendas agrícolas podem estimular a prática da pluriatividade. Conforme Schneider (2007) em contextos em que a agricultura se torna altamente modernizada e inserida em padrões de concorrência internacionais, os agricultores tendem a sofrer, cada vez mais, os efeitos da dependência tecnológica, que implica em aumentos frequentes e compulsórios dos custos de produção agrícola. Com isso o agricultor pode envolver-se com outros tipos de ocupações, sendo ela agrícola ou não.

A própria mudança no mercado de trabalho pode ser um fator estimulante para práticas pluriativas, conforme destacado no quarto fator da Figura 02, que para Schneider (2007) é uma tendência mais geral, a expansão da pluriatividade no meio rural também pode ser atribuída à dinâmica do mercado de trabalho não agrícola de algumas regiões. Existem vários estudos sobre os processos de descentralização de indústrias para espaços rurais, mostrando seu significativo impacto na geração de empregos. Essas mudanças podem permitir que algum membro da Unidade de Produção Familiar desenvolva atividades, diretas ou indiretas para as indústrias.

O quinto fator são as políticas de desenvolvimento rural, que estimulam atividades não agrícolas no meio rural tais como o turismo, as pequenas e médias indústrias, a preservação ambiental, entre outras. Essas políticas estão presentes mais em países desenvolvidos, nos quais a pluriatividade é tratada como algo importante a ser estimulado para os agricultores. Segundo Schneider (2007, p.13) afirma que:

Em geral, são políticas que visam gerar empregos, estimular a diversificação das rendas e oferecer alternativas econômicas aos agricultores que não sejam exclusivamente ligadas ao aumento da produção, fazendo com que possam reanimar as regiões desfavorecidas ou pouco competitivas.

Por último a pluriatividade pode ser considerada uma característica intrínseca a agricultura familiar, além de ser uma estratégia de reprodução. "Assim, à medida que amplia-se o reconhecimento da importância da agricultura familiar, também se amplia a atenção sobre a pluriatividade". (SCHNEIDER, 2007, p.14).

Segundo Nascimento (2008) a pluriatividade pode apresentar-se como uma estratégia importante a somar forças para potencializar um novo padrão de desenvolvimento rural para o país, um modelo mais socialmente includente, assentado na agricultura familiar. 
Baseado nas chamadas "virtudes da pluriatividade", discutidas por Graziano da Silva (2000), Schneider (2003) e Sacco dos Anjos (2003) podemos chegar ao seguinte, como demonstra a Figura 03:

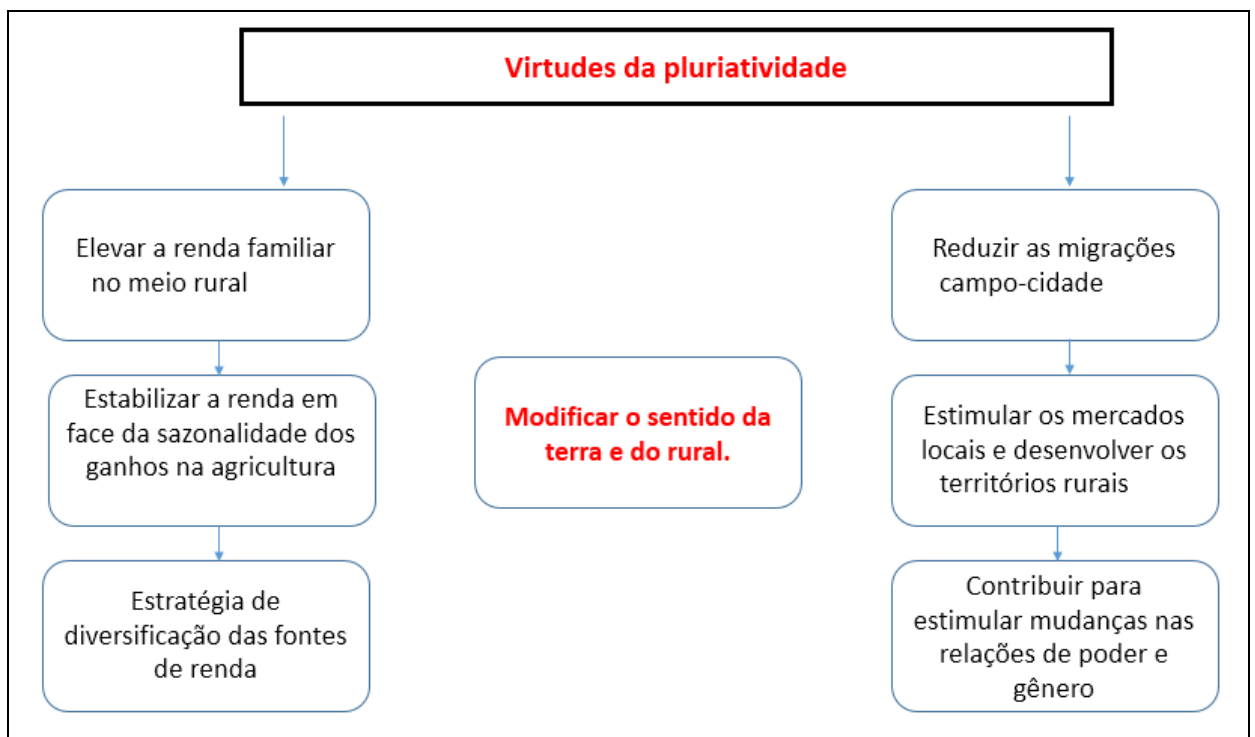

Figura 03: Virtudes da pluriatividade.

Organizado por SOARES, J.A.P (2016).

As virtudes da pluriatividade existem, no entanto, a função agrícola do campo não pode ser esquecida, ela deve atuar como parceira das atividades agrícolas, como complementariedade e não como substituto das atividades agrícolas típicas do campo, sendo que, "para ser considerada pluriativa, a unidade de exploração familiar deve ter algum membro da família envolvida em atividades não agrícolas, e ao mesmo tempo, manter o trabalho agrícola" (CANDIOTTO, 2007, p.196)

\section{Estudos da pluriatividade no Brasil.}

Os pesquisadores brasileiros que iniciaram a pesquisa sobre a pluriatividade a partir da década de (1990), destacam-se: Anjos, em (1995); Carneiro, em (1993 e 1996); Neves, em (1995 e 1997); e Schneider, em (1994 e 1995), além dos estudos coordenados por José Graziano da Silva sobre o "novo rural brasileiro", termo usado em virtude da emergência expressiva das atividades rurais não agrícolas no meio rural brasileiro.

Ao analisar a pluriatividade no Brasil é necessário que haja uma adaptação à realidade brasileira, uma vez que o espaço rural francês apresenta dicotomias em relação ao do Brasil. Guanzirolli (2001) alerta quanto à importância de se considerar a diferenças existentes entre esses dois países, segundo ele: 
Numa falsa analogia com o que se passou nos países capitalistas centrais, o aumento das ocupações rurais não agrícolas no Brasil tem sido visto por grande parte das elites (incluindo as intelectuais) como uma evidência do desenvolvimento. Falsa analogia, uma vez que não são levadas em conta as diferenças radicais nas condições em que estes fenômenos ocorreram em ambos os casos. (GUANZIROLLI, 2001, p.18).

O autor não apresenta uma opinião contrária a pluriatividade, num entanto, faz uma ressalva para a importância de se levar em consideração as particularidades do Brasil e não apenas implantar teorias de outras realidades.

A pluriatividade pode ocorrer em todas as regiões do país, o que será mutável são os motivos que estão associados à sua prática, variando de acordo com a realidade de cada região. Como afirma Nascimento:

\begin{abstract}
A pluriatividade é um fenômeno social "encontrável" em todo território nacional. Em cada subespaço territorial regional haverá uma explicação para cada especificidade local da existência (estática) da pluriatividade. (NASCIMENTO, 2008, p. 29).
\end{abstract}

A ocorrência de atividades não agrícolas no meio rural e a ocupação das famílias em atividades não agrícolas vêm se destacando no cenário agrário brasileiro e alterando a dinâmica no espaço rural brasileiro. Todavia, conforme Anjos (2003), para apreender as várias manifestações da pluriatividade, é preciso considerar as especificidades geográficas, econômicas, políticas e sociais de cada país. Numa perspectiva geográfica é relevante considerar as especificidades do lugar, uma vez que o Brasil apresenta lugares heterogêneos, com paisagens e vegetações diferenciadas, onde, as atividades pluriativas podem ser distintas. Sobre as especificidades envolvendo a pluriatividade Silva (2015) coloca que:

Assim, a pluriatividade seria um fenômeno resultante de um amplo processo de transformação agrícola inteiramente ligado à dinâmica geral da economia (divisão do trabalho), mas que guarda certas especificidades de acordo com as condições geográficas existentes e os contextos políticos e econômicos nos quais as Unidades Familiares estão inseridas. (SILVA, 2015. p.24)

As práticas pluriativas podem ocorrer em todas as regiões brasileiras, a forma, não obstante, como essas se aplicam são heterogêneas, uma vez que, o Brasil é um país extenso com diversidades climáticas, naturais, políticas e econômicas, a forma de abrangência é que poderá variar.

A pluriatividade pode ser uma realidade presente tanto nas grandes propriedades como em pequenas, neste texto opta-se em discutir a pluriatividade na agricultura familiar, que nem sempre vão estar ligadas apenas ao capital, podem ter viés de permanência, continuidade e sobrevivência no campo. Segundo Schneider (2003. p.114), 
“[...] para se entender o significado da pluriatividade em situações onde predomina Agricultura Familiar é preciso admitir que determinadas formas sociais se transformam, se metamorfoseiam e se reproduzem fora do escopo rígido das leis de valorização do capital".

No Brasil o Censo Agropecuário faz a classificação dos estabelecimentos por tipo de atividades, considerando: atividades agropecuárias, não agropecuárias, e agropecuárias e não agropecuária ao mesmo tempo. O que o IBGE (2006) considera como propriedade agropecuária é toda aquela que:

"O cultivo do solo com culturas permanentes e temporárias, inclusive hortaliças e flores; a criação, recriação ou engorda de animais de grande e médio porte; a criação de pequenos animais; a silvicultura ou o reflorestamento; e a extração de produtos vegetais".

Estabelecimentos não agropecuários são aqueles cujas atividades não tem relação com cultivos de plantas ou criação de animais. Os estabelecimentos Agropecuários e Não agropecuários são aqueles que, para compor a renda familiar, praticam ambas as atividades ao mesmo tempo.

Os números relativos a essa classificação estão expressos na Tabela 01 e 02 , foram divididos por regiões como está especificado a seguir:

Tabela 01: Estabelecimentos em que o produtor declarou ter atividade fora do estabelecimento por tipo de atividade, segundo a Agricultura Familiar - Brasil (2006).

\begin{tabular}{|c|c|c|c|c|}
\hline \multirow{3}{*}{$\begin{array}{c}\text { Agricultura } \\
\text { Familiar } \\
\text { Regiões }\end{array}$} & \multicolumn{4}{|c|}{$\begin{array}{l}\mathrm{N}^{\circ} \text { de Estabelecimentos em que o produtor declarou ter atividades fora do } \\
\text { estabelecimento. }\end{array}$} \\
\hline & \multirow[b]{2}{*}{ Estabelecimentos } & \multicolumn{3}{|c|}{ Tipo de atividade } \\
\hline & & Agropecuário & $\begin{array}{c}\text { Não } \\
\text { agropecuário }\end{array}$ & $\begin{array}{c}\text { Agropecuário e } \\
\text { Não } \\
\text { agropecuário }\end{array}$ \\
\hline Norte & 90.768 & 39.148 & 48.021 & 3.599 \\
\hline Nordeste & 556.671 & 313.176 & 226.874 & 16.621 \\
\hline Sul & 210.043 & 86.998 & 107.188 & 4.787 \\
\hline Sudeste & 204.497 & 93.544 & 105.926 & 5.027 \\
\hline Centro-Oeste & 63.083 & 24.289 & 36.846 & 1.948 \\
\hline TOTAL & 1.125 .065 & 557.155 & 524.855 & 31.982 \\
\hline
\end{tabular}

Fonte: Censo agropecuário 2006 (IBGE), organizado por SOARES, J.A.P (2016) 
Tabela 02 - Estabelecimentos em que o produtor declarou ter atividade fora do estabelecimento por tipo de atividade, segundo a agricultura não familiar - Brasil (2006).

\begin{tabular}{|c|c|c|c|c|}
\hline \multirow{2}{*}{$\begin{array}{c}\text { Agricultura } \\
\text { Não } \\
\text { Familiar }\end{array}$} & \multicolumn{4}{|c|}{$\begin{array}{l}\mathrm{N}^{\circ} \text { de Estabelecimentos em que o produtor declarou ter atividades fora do } \\
\text { estabelecimento. }\end{array}$} \\
\hline & \multirow[b]{2}{*}{ Estabelecimentos } & \multicolumn{3}{|c|}{ Tipo de atividade } \\
\hline Regiões & & Agropecuário & $\begin{array}{c}\text { Não } \\
\text { agropecuário }\end{array}$ & $\begin{array}{l}\text { Agropecuário e } \\
\text { Não agropecuário }\end{array}$ \\
\hline Norte & 23.352 & 7.187 & 3.143 & 1.103 \\
\hline Nordeste & 135.917 & 55.130 & 28.913 & 5.582 \\
\hline Sul & 67.014 & 23.968 & 40.563 & 2.483 \\
\hline Sudeste & 99.443 & 31.077 & 64.318 & 4.048 \\
\hline $\begin{array}{l}\text { Centro- } \\
\text { Oeste }\end{array}$ & 39.642 & 12.142 & 25.589 & 1.911 \\
\hline TOTAL & 365.368 & 129.504 & 162.526 & 15.127 \\
\hline
\end{tabular}

Fonte: Censo agropecuário 2006 (IBGE); Organização: SOARES, J.A.P, 2016.

A redução de pessoas envolvidas com atividades agropecuárias já haviam sido observadas desde a decáda de 2000, o que pode ser justificado através da Campanhola e Graziano Silva (2000) que destacam que a queda da PEA rural ocupada em atividades agrícolas e crescimento da PEA rural ocupada em atividades não agrícolas se deve a vários fatores, dentre eles os que merecem destaque, são: a crescente modernização dos sistemas produtivos que libera mão de obra das atividades agropecuárias e a própria queda da renda oriundas das vendas dos produtos agrícolas e pecuários. Isso possibilita que pessoas residentes nos domícilios rurais busquem novas formas de inserção produtiva, seja ocupando-se exclusivamente nas "novas" atividades agrícolas e não agrícolas desenvolvidas dentro ou fora do estabelecimento rural.

Os dados expostos nas Tabelas 1 e 2 retratam que as práticas agropecuárias e não agropecuária, ou seja, praticas pluriativas, estão presentes em todo o território brasileiro, no entanto, em menor quantidade que as demais atividades. A Região Nordeste é onde essas práticas são mais evidentes. Segundo Nascimento (2008. p.31) a persistência e o crescimento da pluriativdade se explicam pela sua relação com o próprio quadro predominante de pobreza na região resultante de um sistema econômico regional, marcado pela ausência de descontinuidades nos seus processos de reprodução econômica. 


\section{A presença da pluriatividade em assentamentos rurais: estudo nos Assentamentos Agrovila Rio Verdinho em Rio Verde (GO) e Nossa Senhora de Guadalupe em Jataí (GO)}

Esse artigo, é parte de uma dissertação de mestrado do Programa de Pósgraduação em Geografia da UFG regional Jataí, realizado em dois assentamentos na Microrregião Geográfica Sudoeste de Goiás em municípios distintos, sendo Assentamentos Agrovila Rio Verdinho em Rio Verde (GO) e Nossa Senhora de Guadalupe em Jataí (GO).

Rio Verde e Jataí, municípios do estado de Goiás, se destacam na prática do agronegócio, portanto, compreender o comportamento das atividades pluriativas nos respectivos municípios é um grande desafio. O primeiro assentamento citado, é localizado em Rio Verde, existe há dezoito anos, conta com 27 famílias das quais foram entrevistadas 25, dessas nove tinham ocupação agrícola e 16 ocupação pluriativa. $\mathrm{O}$ segundo assentamento, é no município de Jataí, possui nove anos de oficialização, conta com 58 famílias, das quais foram entrevistadas 25 famílias, partindo de uma amostragem aleatória simples, para que não houvesse interferências no resultado final. Das famílias entrevistadas nesse assentamento 15 são agrícolas e apenas 10 são pluriativas. Alguns pontos foram indicados como provável justificativa da ocorrência de maiores famílias pluriativas no assentamento Agrovila Rio Verdinho do que no Nossa Senhora de Guadalupe:

- A data de criação, o primeiro assentamento possui dezoito anos, já está em via de emancipação, alguns moradores já deram entradas na documentação para posse definitiva. O segundo é relativamente novo, possui apenas nove anos, está em via de formação e alguns benefícios voltadas para as políticas públicas ainda não chegaram, como por exemplo, o acesso ao PRONAF, causando nesses moradores receio em desempenhar atividades que possam ferir as normas do INCRA.

- O primeiro (Rio Verde) assentamento apresenta em sistema de Agrovila e possui uma parte das terras (16 hectares) em regime comunitário, o que levou muitos moradores a terceirizar a plantação, ou seja, arrendar ou plantar em parceria, deixando membros da família ociosos, fazendo com que esses buscassem novas ocupações nem sempre agrícolas.

- O assentamento possui uma escola que acaba empregando alguns moradores do próprio local, no caso nove moradores trabalham na escola sendo funcionário público efetivo, contratado ou mesmo como prestadores de serviços.

- No segundo assentamento (Jataí) o fato da proximidade com a cidade permite com que os assentados saiam de suas casas pela manhã para trabalharem na cidade, praticando a migração pendular, sejam como comerciantes por conta própria, seja como trabalhadores no comércio com CTPS assinada, carpinteiro, pedreiro, jardineiro, diarista e etc. 
- Em ambos os assentamentos a prestação de serviços também é muito presente, devido ao alto custo de produção agrícola e o baixo custo do produto agrícola, faz com que famílias que conseguiram adquirir equipamentos utilizados nas atividades agrícolas prestem serviços para aquelas que não podem ou preferiram não obtê-los.

Durante a realização do trabalho a campo constatou uma pluralidade de atividades econômicas no Assentamento Agrovila Rio Verdinho em Rio Verde (GO) e Assentamento Nossa Senhora do Guadalupe em Jataí (GO). Essas atividades foram classificadas em 10 grupos, como segue:

$\left.1^{\circ}\right)$ Produção agrícola própria: considerou-se aqueles moradores que plantam e colhem utilizando a força de trabalho familiar, equipamentos próprios ou alugado, normalmente voltadas para soja e milho, em dois momentos safra e "safrinha" e destinadas ao Programa de BIODISEL.

$2^{\circ}$ ) Produção agrícola com parceria/arrendamento: compõem esse grupo de famílias agricultoras que contam com parcerias para plantar ou arrendam a terra, tanto no uso de equipamentos como no trabalho, há divisão nos lucros e prejuízos entre o proprietário da terra e seu parceiro/arrendador.

$3^{\circ}$ ) Produção Leiteira: corresponde a esse grupo de famílias que tem o leite como atividade econômica, entretanto nesse assentamento (Agrovila) apenas dois moradores tem resfriador o que faz com que outros moradores os quais tenham a mesma atividade deixem o leite em um desses resfriadores, para ser entregue a Samarino (empresa queijeira que atua no munícipio de Rio Verde) a qual passa nos pontos de coleta quatro vezes por semana. Os moradores que utilizam o resfriador auxiliam no pagamento da energia elétrica.

$4^{\circ}$ ) Trabalhador com CTPS assinada/ Funcionário público (efetivado ou contratado): esse grupo engloba os trabalhadores em propriedades rurais voltadas para a agricultura empresarial (nas redondezas do assentamento) com Carteira de Trabalho assinada, empregados em indústrias e funcionários públicos efetivados que trabalham na escola localizada no assentamento e outros que por ventura enquadrar nesse item.

$5^{\circ}$ ) Locador: comum nesses assentamentos são os moradores construírem em seus lotes casas que são alugadas e servem como complemento de renda. Essas casas são alugadas para parentes e de algum outro morador do assentamento que queiram viver no campo.

$6^{\circ}$ ) Aposentado ou pensionista/Bolsa família: são as pessoas que recebem rendas sociais como aposentadorias ou pensões pagas pelo FUNDO RURAL ou INSS, por idade, viuvez, tempo de serviço ou invalidez e auxilio social como bolsa família.

$7^{\circ}$ ) Prestadores de serviços: engloba nesse grupo trabalhadores que atuam como prestadores de serviços em trabalhos rurais como diaristas em outros lotes no próprio assentamento ou em propriedades vizinhas, pessoas que desenvolve o trabalho de diaristas em outras residências no próprio assentamento, além de eletricistas, 
encanadores, marceneiro, que prestam serviços no assentamento ou na cidade sem vínculo empregatício.

$8^{\circ}$ ) Comerciante: nesse grupo foram colocados os proprietários de lotes que possuem pequenos mercados de secos e molhados para atender os moradores das redondezas e do próprio assentamento; proprietário de salão de beleza, confecção, vendedores de produtos de beleza e vasilhas em revistas ou pronto entrega, comércio no ramo de alimentos na cidade (vendas de pequi e cachorro-quente por exemplo).

$9^{\circ}$ ) Criação e venda de animais e atividade para-agrícola: fazem parte desse grupo moradores que vendem suínos e aves na porta ou entregam na cidade, além de queijos, doces, ovos e outros tipos de mantimentos retirados do próprio lote.

$10^{\circ}$ ) Caminhoneiro/ Freteiro/Transporte escolar: grupo de pessoas que possuem caminhão ou outro tipo de veículo e fazem frete dentro do próprio assentamento ou fora dele, além de moradores que possuem Vans, Kombis, ônibus, micro-ônibus que são utilizados como transportes escolares.

Algumas atividades não agrícolas encontradas nos assentamentos pesquisados podem ser observadas na Figura 04.

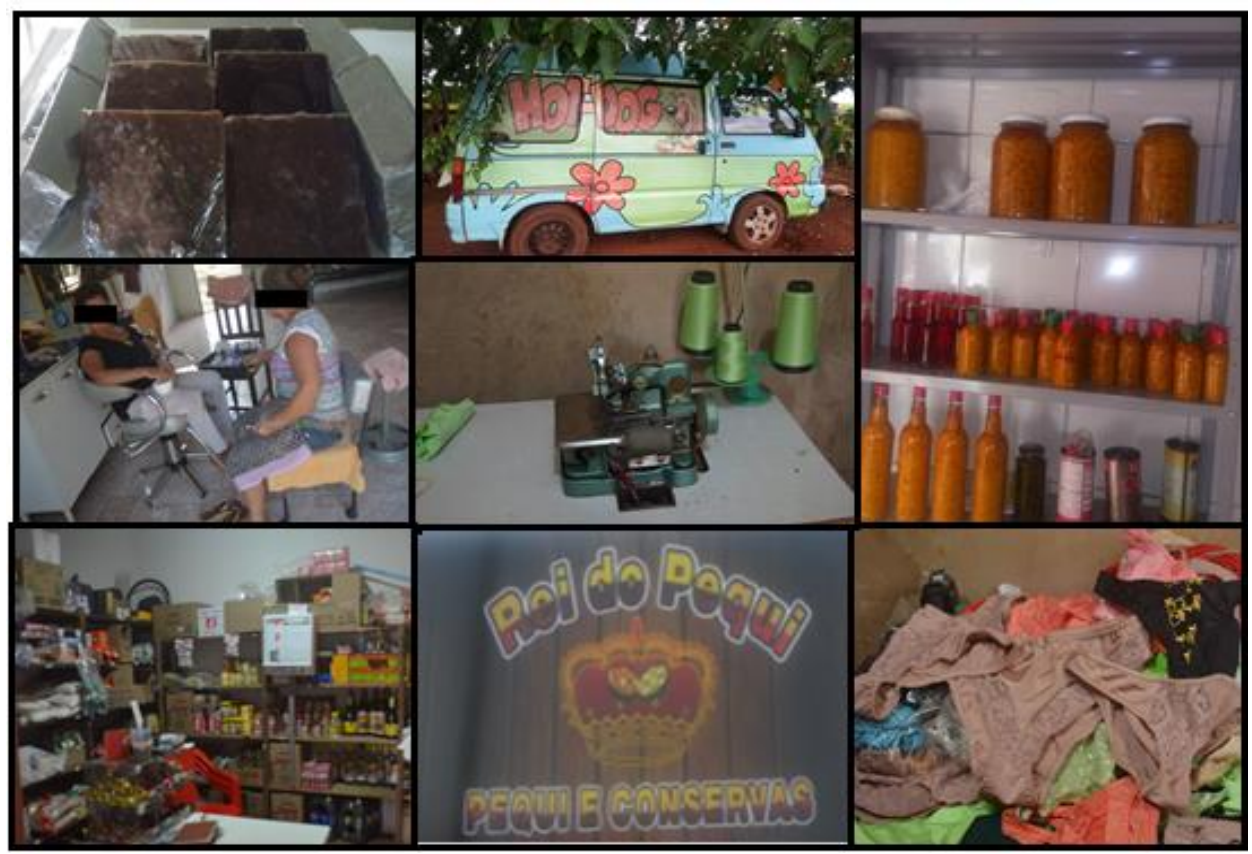

Figura 04: Atividades não agrícolas praticadas por moradores dos Assentamentos Agrovila Rio Verdinho e Nossa Senhora de Guadalupe.

Fonte: Trabalho de Campo. SOARES, J.A.P, 2016. 
As atividades não agrícolas possuem uma participação importante na formação da renda familiar dessas famílias, representam mais de $50 \%$ da renda total. Sendo assim, a prática não agrícola é um importante meio para agregar valor às atividades agrícolas, esse fato foi confirmado em ambos os assentamentos, de acordo com os próprios entrevistados.

Verificou-se que a prática não agrícola nos lotes pluriativos, em ambos os assentamentos são praticadas principalmente pelos jovens que se encontram na faixa etária de 18 - 30 anos, fato importante que corrobora com a continuidade do jovem no meio rural, outro fato relevante é que as pessoas que praticam atividades não agrícolas possuem um grau de escolaridade maior que as envolvidas apenas com atividades agrícolas.

Os motivos que induzem as famílias nas práticas de atividades não agrícolas são variados, entre eles destaca-se: mão de obra obsoleta; renda da terra insuficiente; estabilidade de trabalho; complemento de renda; composição familiar (muitos membros compõem a família); retorno dos filhos com a família já formada; por opção (realização pessoal); falta de acesso a políticas públicas para investimento na terra; alto custo agrícola (para plantar) / baixo preço agrícola (para comercializar); aumento do custo de vida e permanência no campo.

Ao questionar os moradores se as práticas pluriativas contribuem com permanência no campo, os moradores responderam como segue na Figura 05:

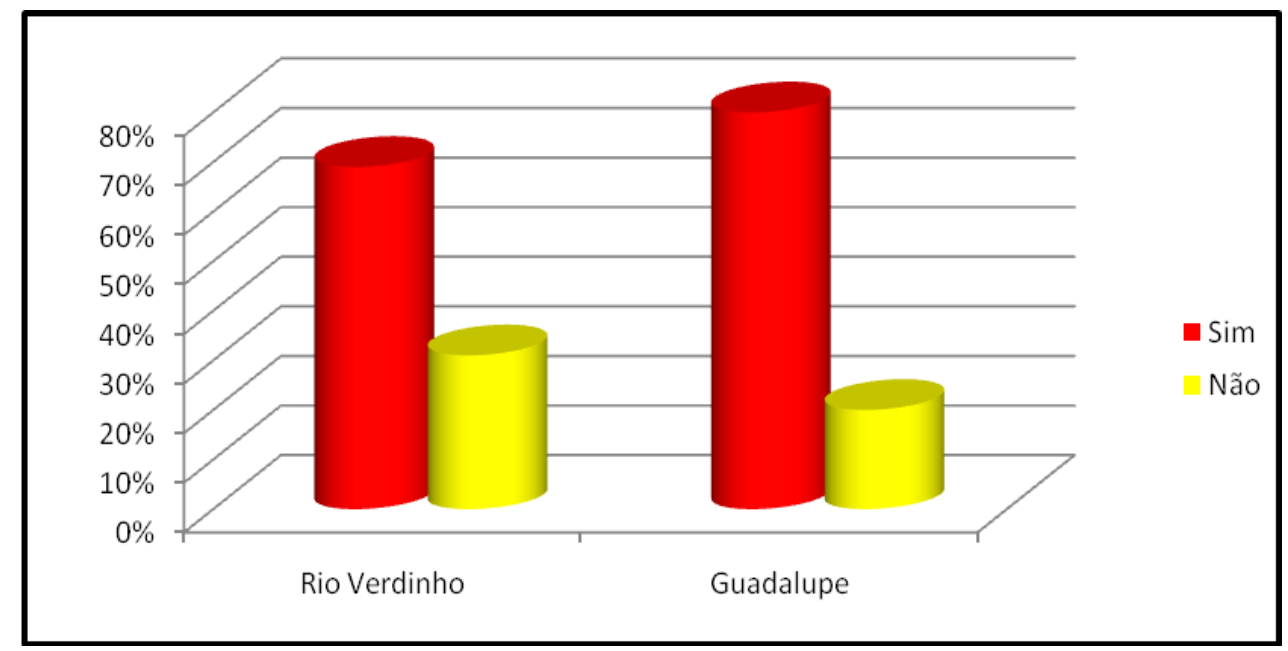

Figura 05: A pluriatividade é importante para sua permanência no campo?

Fonte: Trabalho de Campo. Org. por SOARES, J. A. P (2016)

Diante das informações levantadas empiricamente compreende-se que a pluriatividade pode ser considerada uma estratégia familiar, colaborando com a permanência do agricultor familiar no campo. 
Acredita-se que essa realidade constatada não interfere na essência do agrícola, ao contrário ela vem fortalecer, porque para que uma família viva em situação de pluriatividade a principal atividade tem que ser a agrícola, todavia permanecer no campo, e continuar tendo uma vida no rural é primordial para essas famílias, mesmo que para isso tenham que desenvolver atividades não agrícolas. De acordo com Lacombe (1984, p. 35-54) há sim uma mudança nas famílias agrícolas clássicas que era visto como "uma propriedade = uma família $=$ uma atividade $=$ uma renda" passando a ser analisada como "uma propriedade = uma família = várias atividades = várias rendas".

\section{Considerações finais}

Com o avanço tecnológico no campo, com a predominância do agronegócio no país, as supervalorizações das terras fizeram com que o agricultor familiar buscasse formas diferenciadas de permanecer no campo e continuar a sua reprodução social, principalmente em assentamentos, que normalmente são áreas pequenas. Diante desse cenário a pluriatividade surgiu como uma forma de reprodução social que permite a continuidade da família no campo, e ainda uma nova opção de complemento de renda.

É notável que as práticas pluriativas estejam presentes em todas as regiões brasileiras, o que varia é o objetivo para qual são desenvolvidas, podendo ir desde combate à pobreza rural até à acumulação financeira. Essas práticas estão intrinsicamente ligadas à Agricultura Familiar, servindo como aparato a esse grupo de agricultores rurais.

Para que a pluriatividade se concretize de fato no Brasil e com maior ocorrência é necessário políticas públicas viáveis para promover tais práticas, uma vez, que a pluriatividade diminui as migrações campo-cidade e faz com que famílias retomem a vida no campo.

A nova complexidade envolvendo o rural brasileiro emergem "novos atores sociais" que favorece a busca por novas atividades que vão além do agrícola, permitindo a prática de atividades não apenas ligadas ao campo. As práticas pluriativas devem ser consideradas como uma forma de inclusão ou permanência no campo e não de exclusão, pois, para que a pluriatividade ocorra o foco principal deve ser a atividade agrícola combinadas com práticas não agrícolas, ou seja, o agrícola não perde sua prioridade.

A pluriatividade estreita o laço do rural com o urbano, sendo que muitos trabalhadores rurais desenvolvem atividades nas cidades e residem no campo, há uma mudança significativa no modo de vida. Deve-se repensar o rural como espaço de outras agriculturas e também como espaço de vida, de trabalho e de lazer, um rural de pluriatividades, que se forma próximo a pequenas cidades, mas que não perde sua essência.

\section{Referências}

ABRAMOVAY, R. Paradigmas do capitalismo agrário em questão. 1 ed. SP: Editora HUCITEC e UNICAMP, 1992. 
ALENTEJANO, P. R, Pluriatividade: uma noção válida para a análise da realidade agrária brasileira? In: TEDESCO, J.C. (Org). Agricultura familiar: realidades e perspectivas. Passo Fundo: UFP, 1999.p. 148 -173.

ANJOS, F. S. dos. Agricultura familiar, pluriatividade e desenvolvimento rural no Sul do Brasil. Pelotas-RS: Agufpel, 2003.

ARF (Association Ruraliste Française). La pluriactivité dans les familles agricoles. Paris, ARF. 1984.

ARKLETON RESEARCH, INRA \& IAM. (1988), Rural Change in Europe, Research Programme on Farm Structures and Pluriactivity. The Arkleton Trust (Research) Ltd. Proceedings of the Montpellier Colloquium, 6/10 de julho de 1987.

CALAÇA, M. D. W. A. A modernização do campo no cerrado e as transformações sócioespaciais em Goiás campo-território. Revista de geografia agrária, Goiânia, v.5, n.10, p. 312-332, ago. 2010.

CAMPANHOLA, C.; GRAZIANO DA S. J. O Novo Rural Brasileiro: Políticas Públicas. Campinas SP, EMBRAPA-Meio Ambiente /IE-UNICAMP,4 v. 2000.

CAMPANHOLA, C.; GRAZIANO DA S. J. O Novo Rural Brasileiro: uma análise nacional e regional. Jaguariúna, EMBRAPA-Meio Ambiente /IE-UNICAMP, 4. v. 2000.

CAMPANHOLA, C.; GRAZIANO DA S. J. O Novo Rural Brasileiro: uma análise Estadual, Sul, Sudeste e Centro-Oeste. Campinas SP, EMBRAPA-Meio Ambiente /IEUNICAMP,4. v. 2000.

CANDIOTTO, L. Z. P. Pluriatividade: aspectos históricos e conceituais. São Paulo SP, Ed.FC - UNIOESTE, 2007.

CARNEIRO, M.J. Agricultores familiares e pluriatividade: tipologias e políticas. In. Costa, L.F.C., Bruno R., Moreira R. J. (Orgs.) Mundo rural e tempo presente. Rio de Janeiro: Mauad, 1999. p. 323 - 344.

CARNEIRO, M.J.Pluriatividade no campo: o caso francês. Revista Brasileira de Ciências Sociais, São Paulo, v. 11. n.32 ,p.89-105. 1996.

CARNEIRO, M.J . (Org.) Ruralidades Contemporâneas: modos de viver e pensar o rural na sociedade brasileira. Rio de janeiro: Mauad X FAPERJ, 2012.

CHAYANOV, A. V. La organización de la unidad económica campesina. Buenos Aires: Nueva Visión, 1974.

FULLER, A. M. From part-time farming to pluriativity: a decade of change in rural Europe. Londres: Journal of Rural Studies, 6 (4): 361-373, 1990.

GUANZIROLI, C. et al. Agricultura Familiar e Reforma Agrária no Século XXI. Rio de Janeiro: Garamond, 2001. 
KAGEYAMA, A. Pluriatividade e ruralidade: aspectos metodologicos. Economia aplicada, v.2, n.3, p. 515-551, 1998.

KAUTSKY, K. A questão Agrária. Coleção proposta universitária, 3 ed. São Paulo: Proposta Editora, 1980.

LACOMBE, P. La pluriactivité et l' evolution des exploitations agricoles. In:

Association des Ruralistes Français. La Pluriactivité dans les Familles Agricoles. Paris: 1984. P. 35-54

LAMARCHE, H. (coord.). A agricultura familiar: do mito à realidade. Tradução: Frédéric Bazin. Revisão: Maria de Nazareth Baudel Wanderley. Volume II. Campinas, SP: Editora Unicamp, 1998.

LAURENTI, A. C. Terceirização na Produção Agrícola: a dissociação entre a propriedade e o uso dos instrumentos de trabalho na moderna produção agrícola. Londrina, IAPAR, 2000.

MARTINS, J. S. Os camponeses e a política no Brasil. Petrópolis Sobre a teoria dos sistemas econômicos não capitalistas. Rio de Janeiro:Vozes, 1981.

NASCIMENTO, C. A. Pluriatividade, pobreza rural e Políticas públicas: Uma análise comparada entre o Brasil e a União Europeia. Fortaleza (CE), Banco do Nordeste, 2008.

NIEDERLE, P.A. Mercantilização, estilos de agricultura e estratégias reprodutivas dos agricultores familiares de Salvador das Missões. 2007. 219 f. (Dissertação de Mestrado em e Desenvolvimento Rural)-Universidade Federal do Rio Grande do Sul. Faculdade de Ciências Econômicas, Porto Alegre RS, 2007.

OLIVEIRA, A.U. Modo capitalista de produção, agricultura e reforma agrária. São Paulo: Labur Edições, 2007.

PRADO, Jr. C. A questão agrária. São Paulo: Brasilense, 1979.

SCHNEIDER, S. A pluriatividade na agricultura familiar. Porto Alegre: Ed. da UFRGS, 2003.

SCHNEIDER, S. A pluriatividade no meio rural brasileiro: características e perspectivas para investigação. Org. Hubert C. de Grammont. México: Ed. Flacso, 2007.

SILVA, S. P. A agricultura familiar e suas múltiplas interações com o território: uma análise e suas características multifuncionais e pluriativas. Brasília: IPEA (Instituto de Pesquisas Econômica Aplicada), 2015.

TEIXEIRA, V. T. Novos contornos ocupacionais no meio rural fluminense: um estudo sobre a pluriatividade entre agricultores familiares. 2009. 283f. Tese (Doutorado em Economia) Universidade Estadual de campinas - Instituto de Economia Campinas, SP. 2009. 
VEIGA, J. E. da. O Desenvolvimento Agrícola: Uma Visão Histórica. São Paulo: Edusp Hucitec, 1991.

WANDERLEY, M. N. B. Um saber necessário: os estudos rurais no Brasil. Campinas SP: Unicamp, 2011.

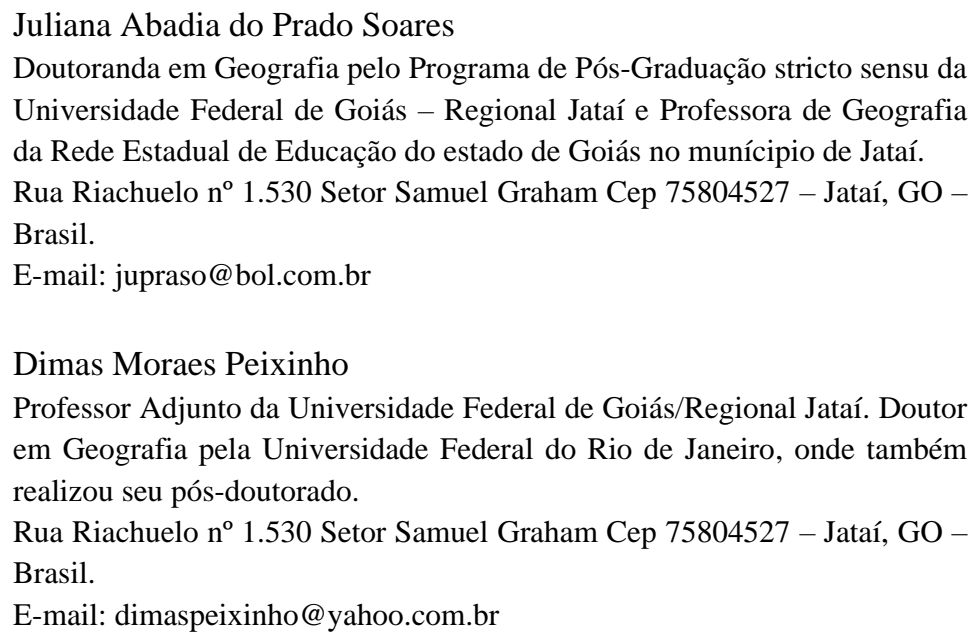

